\title{
Classroom Community and Discourse: How Argumentation Emerges during a Socratic Circle
}

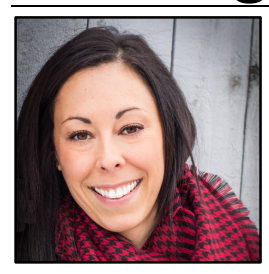

Alexis Carmela Brown

University of Victoria, Canada

\begin{abstract}
Literacy and language development is a central aspect of educational theory and practice. One area of literacy and rowlanguage research that has had a lot of attention is dialogic teaching (Bakhtin, 1984; Freire, 1970; Murphey, Wilkinson, Soter, Hennessey, \& Alexander, 2009; Reznitskaya \& Gregory, 2013). However, there is limited research on how high school students use their classroom discourse to construct meaning, especially in argumentation. The purpose of this data analysis is to investigate the emergence of argumentation literacy in a Socratic circle. Socratic circles, a literacy practice consisting of two concentric circles of students focused around a piece of text, are used to provide students with the opportunity to co-construct meaning through classroom dialogue (Copeland, 2005). The emergence and construction of argumentation is analyzed by applying discourse analysis to a video of a high school classroom,. Findings from this analysis reveal that through the use of exploratory talk, three discourse patterns emerge that are in line with argumentation practices: (1) generalizations, (2) communicative struggles, and (3) coconstruction of ideas. Results of the analysis are discussed to inform theory and instruction on dialogic teaching and the use of Socratic circles to develop argumentation-related forms of literacy.
\end{abstract}

Keywords: dialogic teaching, exploratory talk, literacy, adolescents, argumentation, Socratic circles

Alexis Carmela Brown is a PhD student in the department of Curriculum and Instruction at the University of Victoria, with a focus is in Language and Literacy. She is also a high school teacher and has worked in urban, rural and alternative classroom settings. Her research topics of interest include dialogic pedagogy, socio-cultural theory, critical literacies, and content-area literacy instruction for adolescents and marginalized youth.

\section{Acknowledgements}

I would like to express my sincere gratitude to the editors and peer reviewers who provided insightful and constructive feedback, opened up a dialogue, and encouraged me throughout the revising process. I would also like to thank Deborah Begoray and Sylvia Pantaleo who provided me with invaluable feedback as I worked through this manuscript. Finally, I would like to acknowledge and thank Wolff-Michael Roth for his endless support and encouragement during the analysis and writing process. 


\section{Classroom community and discourse: How argumentation emerges during a Socratic circle}

Alexis Carmela Brown

\section{Introduction}

Teaching critical literacy skills such as argumentation is fundamental to the purpose of student learning because these skills allow for students' civic participation in a democratic society. Researchers in the area of language and literacy have stressed the importance of discussion and dialogue to the formation of critical literacy skills such as argumentation (Abrami et al., 2015; Daniel \& Gagnon, 2011; Jonassen \& Kim, 2010; Reznitskaya \& Gregory, 2013). Specifically, dialogic education, which emphasizes that students' voices are equal to teachers' voices in knowledge creation, is linked to critical literacy development through empowerment and engagement in learning (Alexander, 2008; Fecho et al., 2012; Mercer \& Howe, 2012). Recent studies on dialogic teaching and argumentation practices in the high school setting are primarily focused on students' ability to provide evidence in support of a claim (Reznitskaya et al., 2008; Styslinger \& Overstreet, 2014; Zhang \& Lu, 2014). Scholars argue that the focus on students' ability to provide evidence is the cornerstone to successful argumentation practice (Jonasson \& Kim, 2010; Osborne et al., 2013). However, there is a lack of research in how dialogic learning fosters other argumentation practices such as counter-argument, rebuttal, and evaluation of claims. The purpose of this analysis is to examine how argumentation literacy practices such as counterargument, rebuttal, and evaluation of claims emerge during a Socratic circle.

Socratic circles foster "exploratory talk," an important feature of dialogic learning (Barnes, 1976; 2008). Exploratory talk arises in Socratic circles because Socratic circles are designed to discuss openended questions in order for participants to further their understanding of a topic. In my analysis I present findings that demonstrate how exploratory talk during a Socratic circle functions to aid argumentation practices that include counterargument, rebuttal, and evaluation of a claim. My analysis highlights three discourse patterns that emerge during exploratory talk - generalizations, communicative struggles, and co-constructions of ideas - all of which build on argumentation practices that are valued in academic settings. These discourse patterns demonstrate how students try out ideas, evaluate, co-construct, and adjust their thinking about texts. An illustrative data set illuminates my discussion about the value and function of exploratory talk in secondary level school settings, as well as implications for future research and practice.

\section{Literature Review}

\section{Dialogic Teaching and Exploratory Talk}

Dialogue, or speaking and listening, is a core component of the English Language Arts classroom. Researchers in the field of language and literacy consistently focus on the various aspects of classroom discourse including what kind of discourse is valued in school settings (Alexander, 2008; Aukerman \& Pandya, 2013; Barnes, 2008; Cazden, 2001; Mercer \& Howe, 2012; O'Connor \& Michaels, 2007). For example, Aukerman and Pandya (2013) argue that academic discourse, which is typically seen as the language used within school, has been given primary attention by researchers making this the valued discourse in school. Delpit (2006) terms academic discourse the "language of power" as it can create a problematic dichotomy between home and school discourses. Giving privilege to academic discourse has led to the segregation of large populations of students. Therefore, many researchers are now calling for a more dialogic approach to teaching, where multiple kinds of discourse are valued, discussion is collaborative, and the power of knowledge is shared between teacher and students, in order to help improve literacy and learning in the classroom (Alexander, 2008; Aukerman \& Pandya, 2013; Fecho, Coombs \& McAuley, 2012; Mercer \& Howe, 2012). 


\section{Classroom community and discourse: How argumentation emerges during a Socratic circle}

Alexis Carmela Brown

Scholars such as Alexander (2008), Barnes (2008), and Mercer and Howe (2008) have extensively examined dialogic approaches to teaching, focusing on the types of talk that are fundamental to authentic dialogic learning. The strongest emphasis for enhancing dialogic learning in the classroom is on learning talk, which is how students themselves talk (Alexander, 2008). An important type of learning talk is exploratory talk, defined as "[w]hen young people are trying out ideas and modifying them as they speak, it is to be expected that their delivery will be hesitant, broken, and full of dead-ends and changes in directions" (Barnes, 2008, p. 5). Exploratory talk directly contrasts with presentational talk, which is focused on a particular audience, content, and language to meet the needs of others rather than sorting out ideas for themselves (Barnes, 2008). Exploratory talk does not provide new information; rather students are able to make sense of something by sharing knowledge, explaining options, and examining ideas critically as they are being held publically accountable (Barnes, 2008; Mercer \& Howe, 2012). Mercer and Howe (2012) advocate for future research in the field of dialogic learning in order to examine conceptual change through the use of exploratory talk in classrooms.

\section{Dialogic Argumentation}

Many scholars have also recognized the use of dialogic teaching approaches to enhance argumentation practices (Jonassen \& Kim; Kuhn, 2005; Styslinger \& Overstreet, 2014; Reznitskaya et al., 2008; Zhang \& Lu, 2014). Jonassen and Kim (2010) define argumentation as "the means by which we rationally resolve questions, issues, and disputes and solve problems" (p. 439). To effectively participate in argumentation the following skills are necessary for formulating a reasoned argument: claim, evidence, justification, counterargument, and rebuttal (Jonassen \& Kim; Kuhn, 2005; Styslinger \& Overstreet, 2014; Reznitskaya et al., 2008; Reznitskaya \& Gregory, 2013; Zhang \& Lu, 2014). Jonassen and Kim (2010) advocate for dialogical forms of argumentation on the basis that it is better suited for education than monologic forms of instruction. Dialogic forms of argumentation are better suited because dialogical learning involves multiple perspectives and occurs in discussion with a goal of convincing others of an opinion or seeking compromise. Jonassen and Kim (2010) also maintain that dialogical argumentation promotes productive ways of thinking, problem solving, and conceptual change.

Despite the benefits students gain through argumentation, research has indicated that argumentation skills and practices are lacking among adolescents (Jonassen \& Kim, 2010; Zhang \& Lu, 2014). In a study focused on improving argumentative writing through dialogue, Styslinger and Overstreet (2014) found that middle school learners struggled to support their claims with textual evidence. Zhang and Lu (2014) suggest that adolescents lack argumentation skills because they struggle to understand argumentation structure and discourse. As such, many scholars have advocated for the improvement of argumentation skills and practices in secondary level classrooms (Jonassen \& Kim; Kuhn, 2005; Reznitskaya et al., 2008; Sherry, 2014; Zhang \& Lu, 2014).

\section{Socratic Circles}

In a recent meta-analysis on teaching students to think critically, Abrami et al. (2015) found that opportunities for dialogue, especially in whole-class discussions, were the most notable in the enhancement of critical thinking skills. Educators are using discussion-based activities such as Socratic circles to increase both argumentation skills and dialogic learning (Copeland, 2005; Dunne, 2014; Styslinger \& Overstreet, 2014). Socratic circles are designed to examine open-ended questions in a whole-class discussion so that participants can seek better comprehension of a topic.

The foundations of a Socratic circle are structured around a piece of text that students have read critically. Students sit in two concentric circles, where the inner circle focuses on examining and 


\section{Classroom community and discourse: How argumentation emerges during a Socratic circle}

Alexis Carmela Brown

discussing the text, and the outer circle listens and observes, and then provides feedback to the inner circle discussants. The feedback provided by the outer circle to the inner circle is meant to focus on the process of quality discussion rather than on the content of the discussion (Copeland, 2005). Both circles have a chance to reflect, and then the students change places and roles so that the process can repeat itself (Copeland, 2005). Socratic circles are aimed at turning the majority of ownership, conversation, and material over to students to increase learning and allow for true dialogue to occur. Additionally, Reznitskaya et al. (2008) note the importance of discussion that is not managed by the teacher through raising hands or selecting the speaker. Thus, Socratic circles function as a dialogic activity that can be included in the learning talk repertoire.

Although the use of Socratic circles as a teaching tool has been previously advocated for in literacy and learning communities, there are a limited number of studies conducted using Socratic circles to support dialogic teaching at the secondary school level (Dunne, 2014; Highman, Brindley, \& Van de Pol, 2014; Styslinger \& Overstreet, 2014). Highman, Brindley, and Van de Pol (2014) argued that no studies have focused on "the distinct challenges and affordances of promoting dialogue in secondary context, nor exploring the notion that the nature of dialogues may be linked to subject epistemology" ( $p$. 88). They further conducted research to determine why dialogic education research is predominantly in the primary school settings (Highman et al., 2014). Highman et al. (2014) advocate for more studies that explore dialogic teaching in secondary-level classrooms, while also acknowledging complications in dialogic teaching at the secondary-level such as organizational, psychological, and assessment pressures.

In drawing on the concepts of dialogic teaching pedagogy, argumentation practices, and Socratic circles, my analysis seeks to join theory and practice by examining how teachers can increase learning talk in the classroom to improve students' critical literacy and argumentation practices. Examining how teachers can increase learning talk in the classroom and improve student argumentation practices is especially significant to secondary level settings, where argumentation practices are a highly valued discourse, but students' use of these practices are lacking. In this analysis, I provide evidence that the use of Socratic circles as an appropriate dialogic teaching tool simultaneously increases learning talk and supports critical literacy and argumentation practices.

\section{Theoretical Framework}

There are two theoretical frameworks guiding this analysis. The first framework is socio-cultural theory as developed by Vygotsky (1978) and expanded by Gee (1992, 2002, 2003). The second framework is critical literacies as derived from Freire's (1970) work on critical theory, and later discussed by Luke (2012).

According to Vygotsky (1978), language and learning is developed socially and through the use of cultural tools. It is through social activity, the use of tools, and guided practice, that an individual constitutes internal thoughts. Cultural tools, which include dialogue, are developed out of ways of thinking, to aid in organizing thought and language development. Gee $(1992,2002,2003)$ articulates that socio-cultural theory contains underlying assumptions that the mind is social, learning is embedded in cultural practices, and meaning is always situated. Gee (1992) uses the terms "Discourse" with a capital $\mathrm{D}$ and "discourse" with a lower case $d$ to explain how socio-cultural theory is applied to learning. In this context, "Discourse" is the cultural group or community that one can participate as a member and "discourse" is how those members communicate. Gee (1992) argues that, if meaning is always situated, then members participating within a particular community "Discourse" have their own set of norms, values, beliefs, and ways of speaking "discourse". Being an active participant in a Discourse also means 


\section{Classroom community and discourse: How argumentation emerges during a Socratic circle}

Alexis Carmela Brown

that the discourse being utilized is accessible and understood by the members. Additionally, in order to be literate within a Discourse one must be able to be an active participant and demonstrate competency.

The second framework is critical literacies, based on Freire's (1970) critical theory and research. Freire (1970) argued that learners' lives and knowledge were not taken into consideration in learning situations. He advocated for a dialogical approach to literacy, in which a reciprocal exchange of information balances the relationship of teacher and learner. Within a dialogic discussion, learners' concerns can be addressed and then goals established for their education in concert with teachers. Luke (2012), influenced by critical theory, uses the term critical literacies to define "the technologies of print and other media of communication to analyze, critique, and transform the norms, rule systems, and practices governing social fields of everyday life" (p. 5). Luke (2012) argues that critical literacies are situated in the use of literacy for social justice as it functions as a critique of dominant ideologies, cultures, economies, institutions, and politics. The use of critical literacies is to bring a balance of power between learner, teacher and text (Luke, 2012).

\section{Method}

The purpose of this data analysis is to investigate the emergence of argumentation literacy practices during a Socratic circle. Two considerations were made in determining the type of data for this analysis: 1) preparation time for a Socratic circle to occur; and, 2) length of a Socratic circle discussion. First, the amount of preparation time it takes by the teacher and students in order for students to engage in a Socratic circle will vary, depending on the amount of pre-activities and exposure students have previously had with dialogue in the classroom (Copeland, 2005). Copeland (2005) suggests that integrating some dialogue elements into pre-existing activities, as well as having students critically read text and prepare prior to a Socratic circle discussion will enhance the dialogue that occurs. Nonetheless, it is the assumption that some level of preparation will have occurred by the teacher and the students in order to make a Socratic circle discussion happen. Second, Copeland (2005) suggests that a minimum of three to five minutes of time should be allocated to discuss one question, and that two questions should be made available so that the total Socratic circle discussion time can be approximately ten minutes. As such, an analysis of a Socratic circle discussion between five to ten minutes will sufficiently demonstrate the emergence of argumentation literacy practices.

\section{Data Collection}

In considering both preparation time and length of discussion, the data source used for this analysis was taken from Youtube. The video entitled "EHS English $2 \mathrm{P} / 1^{\text {st }}$ Socratic Seminar Q1" is seven minutes in length, and has been transcribed using ExpressScribe software (see Appendix). The video clip includes the features of a Socratic circle according to Copeland (2005), with two concentric circles, and the use of an open-ended prompt for discussion. The video was recorded in a secondary level English language classroom.

YouTube, a social network website, provides opportunities for public interaction as a producer, viewer, or both. (boyd \& Ellison, 2007; Giglietto et al.2012;. Karpf, 2012; Lange, 2007). Giglietto et al.'s (2012) literature review on the uses of Youtube as a data source suggest "Youtube videos usually define particular communities producing specific contents for the members of a community"(p. 149). As such, the purpose of this particular video is for an education community, and more specifically to demonstrate the use of a Socratic Circle in an English Language Arts high-school classroom. The title "EHS English 2P / $1^{\text {st }}$ Socratic Seminar Q1" functions as tags and key words for searching. The video is also 


\section{Classroom community and discourse: How argumentation emerges during a Socratic circle}

Alexis Carmela Brown

categorized as "Education," and the description of the discussion question is made available as part of the video context.

Further, the producer of the video, Msapigo, assumed to be the teacher who is recording and timing this particular discussion, has four other videos on her Youtube site, each with the same group of students in a Socratic circle. It is clear through viewing the other videos that the students have been prepared for a Socratic circle discussion by the notes they are referring to on their desks (turns 1, 2, 3, 4, $38,59,72$ ) and by the way they ask each other to participate (turns $9,16,30,42$ ) in the discussion during silent periods (Copland, 2005).

\section{Participants}

The participants in the video are grade 11 students in an English Language Arts classroom in the United States. They are set-up in a Socratic circle formation, with an inner circle of 13 students, and an outer circle of 12 students. There are 14 boys and 11 girls.

\section{Setting}

The students are in a classroom, sitting in desks, which have been arranged in two concentric circles. Students in the inner circle have written speaking points and quotations in their notes. Students are discussing the novel Things Fall Apart by Chinua Achebe (1958). They have been provided with the following discussion prompt:

Analyze the Ibo concept of male and female crimes and draw conclusions about the Ibo notion of gender. What is assumed about women? What is assumed about men? Go beyond the concept of crime to find at least two examples from other parts of the novel that support your ideas. Lastly, state your opinion about how women and men should be viewed.

Students engaged in discussing the prompt for seven minutes.

\section{Data Analysis}

Following the procedures suggested by Roth and Hsu (2010), I focused on the discourse that was being used by the students during a Socratic circle. Using open coding (Corbin \& Strauss, 1990), I began my analysis by examining the conversational turns that were being produced by the students. In some cases I explored a single turn, whereas other instances I grouped turns together. The single turns were coded separately when the utterance offered a new idea to the topic. Episodes were grouped together when the utterances being produced were making sense of an ongoing topic. An example of this can be found when looking at turns 3 to 7 :

1 S3: Well umm, I have another quote on page 13, his wife especially the youngest, lived in perpetual fear of his fire-y temper, and so did his little children, and that shows that he really does rule in his household and that everyone under him is treated like they're not treated with enough respect in my point of view

2 S4: And I also believe that men are also providers like umm yams are like an important crop in the lbo culture and a I have a quote umm and it says "yams stood for many of us and he could (survive on yams?) from one harvest to another to another wasn't going to (mumbling word)

3 S5: [Umm I] actually disagree with [S3] with what [S3] was saying earlier, I don't think uh the lower the other people in the family besides Okonkwo are disrespected I just think that if Okonkwo gives off respect and if he feels he is disrespected back he lashes out and ah abusive 


\section{Classroom community and discourse: How argumentation emerges during a Socratic circle}

Alexis Carmela Brown

\section{S3: So what makes you think that that's OK?}

5 S5: It's not OK I'm just saying that I don't really think they are disrespected in the sense of manners, I just think that like you know

Turns 3 and 4 were coded separately as utterances that offered a new idea or topic. In turn 3, S3 suggests that not everyone is treated with enough respect; while in turn 4, S4 argues that men are the providers. Both of the topics brought up in turns 3 and 4 were new to the Socratic circle discussion. However, turns 5 to 7 were grouped together because they were making sense of an on-going topic regarding respect which was previously mentioned in turn 3 .

I had two types of codes following the initial analysis and open coding: a single turn in which an idea was being spoken; and an episode, or group of turns, that were making sense of an idea that had previously been offered. I then started to focus on examples that included forms of exploratory talk. Using Barnes' (2008) definition of exploratory talk, that is, "trying out ideas and modifying them as they speak. . . hesitant, broken, and full of dead-ends and changes in directions, (p.5)" I coded talk that used modifiers such as "I think," "in my point of view," "my idea is," and "I don't think that." An example from the transcript that demonstrates the use of exploratory talk is as follows:

17 S9: Well I think that women are, well it seems that women are the least significant thing to Ibo, and like the men are the most powerful and they control mostly everything just about everything and um they don't get penalized for what they do and they beat their women and stuff so ...

In this turn it can be recognized that "[w]ell I think that" and "well it seems that" are modifiers to an idea. As well, the turn contains broken speech and changes to the student's position with utterances such as "and they control mostly everything just about everything and um. . ." Finally, this turn also demonstrates a dead-end in thought during the utterance "and they beat their women and stuff so ...."

The single turns were subdivided into two categories after the forms of exploratory talk were coded: turns that used exploratory talk with a single idea, and turns that used exploratory talk with multiple ideas. From this point, I began to look for any patterns of discourse that had emerged during the two categories of single turns and the grouped episodes. Further review of the data led to the recognition of three types of discourse patterns. These patterns were coded as generalizations, communicative struggles, and co-construction of ideas. Generalizations came from the use of exploratory talk with a single idea; communicative struggles were grouped turns where utterances were making sense of the ideas; and co-construction of ideas came when exploratory talk was used to merge previous ideas, or merge a previous idea with a new idea.

Finally, I investigated how the exploratory talk discourse generally, and the use of the three discourse patterns specifically, had links to argumentation practices and schemes that are typically valued in academic communities (Reznitskaya et al., 2008; Sherry, 2014). These argumentation practices include claim, warrant, evaluation, evidence, counter-argument, and rebuttal.

\section{Findings}

The findings from this analysis show that the use of exploratory talk during a Socratic circle contributes to the development of more formal argumentation practices. Formal argumentation practices can be linked to the three discourse patterns that emerged, including generalizations, communicative struggles, and co-construction of ideas. There were 78 turns in this discussion. Of the 78 turns, 11 turns were generalizations (turns 5, 17, 19, 20, 23, 38, 43, 47, 49, 52, 60); 53 turns, or 9 episodes, were communicative struggles (turns $6-7,9-15,16,25-37,39-40,44-50,52-58,62-72,75-78$ ); 


\section{Classroom community and discourse: How argumentation emerges during a Socratic circle}

Alexis Carmela Brown

and 10 turns were co-construction of ideas (turns $8,16-17,20,38,41,51-52,59,73$ ). Below, each of the patterns of talk are discussed, demonstrating how they work together and produce discourse in line with argumentation practices such as the use of claims, warrants, evaluation, counter-argument, and rebuttal (Jonassen \& Kim, 2010; Reznitskaya et al., 2008; Zhang \& Lu, 2014).

\section{Generalizations}

Prior to a Socratic circle discussion students will have read a text as well as considered openended questions to guide the topic of the discussion. Students are encouraged to bring notes on their ideas, and provide quotes for textual evidence to support their ideas (Copeland, 2005). By having students prepare their ideas, Socratic circles can allow for some elements of presentational talk, or more formal argumentation discourse. In dialogue, this is heard when students make a claim or present an idea and then back it up with evidence. Although using evidence to support an idea is the primary goal of argumentation, most of the discourse used in this analysis was exploratory, informal, and general in nature. This is in line with Styslinger and Overstreet's (2014) findings in that students often struggle to support their claims with textual evidence. However, generalizations of claims without the use of textual evidence do have an important place in dialogic exchanges as it encourages discussion and critical evaluation of a position.

In the following series of conversational turns, we can see the function of exploratory talk and the use of generalizations to open up a dialogic exchange. This is especially pronounced when exploratory talk (turn 3) is juxtaposed with presentational talk (turns 1 and 2):

1 S1: "Angered by his wife who went to plait her hair at her friend's house and did not return early enough to cook the afternoon meal" this shows that men are violent and boss of their family

2 S2: Well I have another quote, that shows that mean are violent, like in page 38, wait I think wait, yeah 38, Onkonkwo's second wife merely cut a few leaves off the umm banana tree to make some food and she said "so without umm further agreement Onkonkwo gave her a beating" which means that Onkonkwo had like superior and he beats whoever he wants to beat

3 S3: Well umm, I have another quote on page 13, "his wife especially the youngest, lived in perpetual fear of his fire-y temper, and so did his little children", and that shows that he really does rule in his household and that everyone under him is treated like they're not treated with enough respect in my point of view

4 S4: And I also believe that men are also providers like umm yams are like an important crop in the lbo culture and a I have a quote umm and it says "yams stood for many of us and he could survive on yams from one harvest to another to another wasn't going to (mumbling)

5 S5: [Umm I] actually disagree with [S3] with what [S3] was saying earlier, I don't think uh the lower the other people in the family besides Okonkwo are disrespected I just think that if Okonkwo gives off respect and if he feels he is disrespected back he lashes out and is ah abusive

In the first 3 turns of the Socratic Circle, we see what Barnes (2008) terms presentational talk. Presentational talk is shown by $\mathrm{S} 1, \mathrm{~S} 2$, and S3 making claims that are supported by text and in direct response to the original prompt. $\mathrm{S} 1$ starts the discussion by making a claim "that men are violent and the boss of their family," using a reference from the text. S2, in response to $S 1$, further supports the claim that "men are violent" by using a direct quote from the novel, and then provides an inference from the quote that men are superior because "he beats whoever he wants to beat." In turn 3, S3 responds and further contributes to the original claim that men are violent by starting with "[w]ell umm, I have another quote." At this point the first 3 turns have all contributed to each other, showing general agreement using text references to support their claim. 


\section{Classroom community and discourse: How argumentation emerges during a Socratic circle}

Alexis Carmela Brown

However, at the end of the turn 3, S3 adds to the claim of men are violent by saying "everyone under him is treated like they're not treated with enough respect." What is significant here is that S3 ends the turn by saying "in my point of view" which moderates the claim and starts the use of exploratory talk. S3 is testing an idea that she can change, retract, or back out of by stating "in my point of view." The use of exploratory talk also opens up the dialogue, by signaling to others that there could be an alternative point of view; which an alternative point of view can be heard in turn 5 .

By the end of the first 5 turns in the discussion, we see that the first 3 turns have a direct claim and supporting textual evidence. The three claims that build upon and support each other would be presentational talk. There is no alternate perspective until the end of turn 3 , when a new claim is introduced through a moderated speech utterance "in my point of view". The moderated speech utterance changes the type of talk to exploratory talk. The dialogue then lends itself to introducing a counter-argument, and continues with exploratory discourse of "I believe" or "I think" using generalizations to create and open up dialogue. Thus, generalizations function as the starting of claims, but allow the claims to be evaluated by others before considering whether the claim is valid. Further, generalizations open up the dialogue to create space for students to engage in the argumentation practices such as counter-argument and rebuttal; both of which will be discussed in the next section.

\section{Communicative Struggles}

With generalizations being made available through exploratory talk, the dialogic exchange opens up further to allow for argumentation practices such as counter-arguments, rebuttals, and evaluations of claims. These argumentation practices emerge through communicative struggles. Sherry (2014), drawing on Bakhtin's concepts of dialogic conflict, argues that a struggle emerges in language when diverse student perspectives and opinions occur during discussion. A communicative struggle between participants in this analysis usually began when a question was asked of another member seeking an explanation of that member's thinking. These instances are where students seek to understand each other, and what Barnes (2008) argued underpinned learning. In this analysis, communicative struggles consisted of the majority of turns in the discussion and typically occurred as a result of generalizations in the dialogue. An example of a communicative struggle occurs during turns 6 and 7 , in response to turn 5 , where S5 uttered a counter-argument using a generalization:

5 S5: [Umm I] actually disagree with [S3] with what [S3] was saying earlier, I don't think uh the lower the other people in the family besides Okonkwo are disrespected I just think that if Okonkwo gives off respect and if he feels he is disrespected back he lashes out and ah abusive

6 S3: So what makes you think that that's OK?

7 S5: It's not OK I'm just saying that I don't really think they are disrespected in the sense of manners, I just think that like you know

8 S6: [Well] it was OK in their culture, but it wasn't OK in our culture today

In response to the counter-argument made in turn 5, S3 questions S5's claim and asks for an explanation "what makes you think that that's OK?" The discourse used in turn 6 functions to continue the exploratory dialogue by questioning S5's thinking, and makes visible an evaluation of the claim by requesting evidence. This utterance by $S 3$ in turn 6 is a significant feature not only of exploratory talk but also in regards to making argumentation practices accessible to all students participating. As such, argumentation structure becomes available because the discourse being used by the students is understood by each other as demonstrated in turn 7 and 8 , where students begin to co-construct meaning. 


\section{Classroom community and discourse: How argumentation emerges during a Socratic circle}

Alexis Carmela Brown

In turn 7, S5 recognizes that S3 asked a question that is evaluative. The question being asked signals there has been a struggle for understanding with S5 saying "[i]t's not OK," using the discourse that S3 made available in the utterance "what makes you think that that's OK?" S5 goes on to say "I'm just saying" and tries to test their idea again, by creating a counter-argument to the statement made in turn 3. S5 struggles to provide evidence to help justify the claim by saying "I just think that like you know. . ." Under the questioning of S5's idea from S3, S5 utters modifiers such as "I just think" or "I'm just saying" which continue the use of exploratory talk and functions of generalization to keep the dialogue open for the co-construction of meaning.

In turn 8 another student, S6, signals understanding of the struggle and draws on the discourse made available by both S3 and S5. S6 says "well it was OK in their culture but it wasn't OK in our culture today." The first part of the utterance "well it was OK in their culture" draws on the claim made by S5, and then uses "but it wasn't OK in our culture today" which shows the position of S3. S6 makes available that the struggle for understanding is one that involves different perspectives on culture. The statement made in turn 8 then redirects the discussion; where the next set of conversational turns examines the different cultural perspectives. The discussion will then move towards co-construction of meaning, which will be examined in the following section.

The conversational exchange in turns 5 to 8 exemplifies the multiple voices that occur during a dialogic discussion. Within these four turns, students engaged in a communicative struggle that brought together multiple ideas. The function of communicative struggle is one of seeking understanding through explanation, evidence, and evaluation. A communicative struggle makes the concepts of counterarguments, rebuttals, and evaluation of claims available to students. The counter-argument was made in turn 5 when S5 uttered "I actually disagree with . . . I don't think that . . I just think . . .," which makes available a different idea or claim. An evaluation of a claim, where a student was asking for an explanation or evidence, was heard in turn 6 when S3 says, "what makes you think that that's OK?" The question makes explicit the need to justify a generalization, but also functioning as a platform for creating a rebuttal. Upon evaluating the validity of a counter-argument, a student can consider a rebuttal.

In turns 5 to 8 , exploratory talk and the function of generalizations leads to communicative struggles. These struggles help participants seek understanding and build meaning within the discussion. Further, the multiple perspectives add to the dialogue making available argumentation practices such as counter-argument, rebuttal and evaluation of claims.

\section{Co-Construction of ideas}

Through both generalizations and communicative struggles, participants are able to move into coconstruction of knowledge. As stated earlier, Barnes (2008) argued that the function of exploratory talk is so students can make sense of something with the information they already have, co-construct meaning, and determine what can or cannot be done. It is within the act of co-construction that students gain an understanding of what they know and are able to use it to evaluate the relevance of claims. The following episode of conversational turns demonstrates how students co-construct meaning and knowledge through dialogue. The students draw on the Discourse already made available to them in order to synthesize information. Further, in this episode students continue to use exploratory talk, merging patterns of talk such as generalizations and struggles in order to achieve co-construction of meaning:

38 S1: Wait..OK..my idea builds upon [S5]'s idea because it's not it's not really about whether they getting disobeyed or not it's really about like head like it's like not that she is disrespecting them they just have in lbo culture they like have a head game and they like it's not about them being disrespected it's like 


\section{Classroom community and discourse: How argumentation emerges during a Socratic circle}

Alexis Carmela Brown

the principle of it and like while men are the boss women are weak and inferior they don't even own their own children but that like it's not about well respect

39 [S3: what do you mean own your own children?]

40 S1: They don't own their own children as in they don't get enough respect it's not about respect from the men, it's about like how the lbo culture and the men look at how other men look at them, they don't wanna, that's why they have more than one wife, and the wives barely get to do anything it's because like the oracle says so

41 S3: And a man has to earn his respect he can't just get respect he has to earn it by doing something or prove it and that's how the wives come along

In turn 38, S1 articulates that "my idea builds upon [S5]'s idea," which was a claim made earlier in the discussion (turn 5). What is interesting in turn 38 is that $\mathrm{S} 1$ begins to define what something "is not" in order to help define what something "is". Using terms such as "it's not really about," "it's not like," "it's not about," shows that previous claims are being evaluated as not valid and that further testing of claims is needed. S1 suggests that "it's not about whether [men] getting disobeyed" (referring to turn 5) and "it's not about [women] being disrespected" (referring to turns 3, 19, 20, $23-37$ ) it is about how "in the lbo culture they have like a head game" and it is "the principle of it and like while men are the boss women are weak and inferior they don't even own their own children." Here S1 builds upon previous made claims by drawing on them to help define a different claim regarding the lbo culture, in that they have "a game" with "principle" and that women "don't even own their own children." This particular turn shows that S1 has co-constructed meaning of the text based on the discussion that is happening. In turn 38, S1 also uses exploratory talk in articulating "my idea" and a generalization when the new claim is being made, as there is no textual reference or evidence.

In turns 39 and 40, a communicative struggle occurs when S3 asks a question of S1, "what do you mean by ..." When S3 asks the question she makes available that an explanation and justification to the claim is needed. The recognition of the need for explanation and justification is shown when S1 responds to the question in turn 40 . The first part of the utterance in turn 40 is an explanation saying that even though it appears women "do not get enough respect" because "they don't own their own children," the Ibo culture is not concerned about women receiving respect from men, it is about "the men look at how other men look at them." While the second half of the utterance in turn 40 becomes a justification by the fact that men "have more than one wife."

Explanation, evaluation and co-construction of meaning all occur because of a communicative struggle that happens in turns 39 and 40 . This co-construction of meaning continues in turn 41 as S3 signals her understanding by rephrasing the explanation given by $\mathrm{S} 1$, when she says "and a man has to earn his respect he can't just get respect he has to earn it by doing something ..." S3 is drawing on the discourse and ideas about respect, not only made by $S 1$, but throughout the entire discussion (turns 3,5 , $19,20,23-37$ ). In the second half of the utterance by S3, she articulates her understanding of S1's justification of the claim, that the respect issue being discussed is not about men respecting the women but rather men respecting the men, by saying "and that's how the wives come along," referring to the end of turn 40. This turn shows co-constructing of meaning, as S3 builds on ideas that have been previously discussed, and then synthesizes the new claim made by $\mathrm{S} 1$.

During turns 38 to 41 students co-construct meaning by building on previous discourse made available during the conversation. Students continue with patterns of talk such as generalizations and communicative struggles in order to access co-construction of ideas. In following the Discourse, students also make available argumentation practices such as justification and evaluation of claims. Evaluating the relevance of claims is a difficult task for a student who does not know what other claims may exist. 


\section{Classroom community and discourse: How argumentation emerges during a Socratic circle}

Alexis Carmela Brown

Through exploratory talk students make available to each other the multiple voices and therefore produce argumentation practices. It is during the process of co-construction that meaning is made of the information presented. This lends itself as a platform for students to evaluate claims, look for evidence, and construct both counter-arguments and rebuttals to their own ideas.

\section{Discussion}

In the prior section I examined the function of exploratory talk as it led to three patterns of discourse used by the participants: generalizations, communicative struggles, and co-construction of ideas. Further, I argued that each discourse pattern connects to argumentation practices that are often valued in school settings. Below, I situate my findings with regards to previous research on dialogic teaching, Socratic circles and argumentation practices.

\section{Exploratory talk in high school classrooms is significant to argumentation practices}

In the Socratic circle discussion excerpts presented above, the use of exploratory talk was significant in opening up dialogue and creating space for the use of argumentation practices. Barnes (2008) argued that exploratory talk is a way for students to understand ideas in order to learn. Exploratory talk also allows students to try out and explain ideas and position themselves safely so that ideas can be changed, modified, or disregarded. Exploratory talk occurs in a community of learners, where students are using their own informal language to discuss ideas without the influence of the teacher (Cazden, 2001).

Although exploratory talk is informal and leads to generalizations, it also calls for public accountability, thus linking it to argumentation practices. Making knowledge publically accountable, sharing opinions, and examining information critically is part of explaining, justifying, and evaluating a claim. Additionally, sharing relevant information is part of considering counter-arguments and rebuttals to claims. For example, it may be informal for students to ask "what makes you think that?" or "why do you think that?" instead of asking for them to present evidence from the text, but given that some formal argumentation practices have already been put in place, the students are informally asking for textual evidence. Within the discussion, students did not accept many generalizations without a textual reference to support an idea.

In addressing the concerns of Highman et al. (2014) that dialogic education is mostly in primary settings, my analysis begins to demonstrate how exploratory talk has an important place in understanding and learning at the high school level. Further, I suggest that exploratory talk functions as situated way for students to engage in argumentation practices, which is part of the English Language Arts epistemology.

\section{Students' Discourse can be used to demonstrate argumentation structure}

Previous research has pointed to the significance of student's informal Discourse to the learning of more formal academic Discourse (Cazden, 2001; Delpit, 2006; Gee, 1992; 2002; 2003). Cazden (2001) and Gee (1992, 2002, 2003), in their research on discourse/Discourse, focused largely on classroom, community and student discourse. More specifically, both scholars highlight the significance of honouring and utilizing student Discourse in a classroom setting (Cazden, 2001; Gee 2003). Having students use their own Discourse during discussions creates a balance of power in which students can equally contribute and learn from one another (Delpit, 2006; Freire, 1970). Further, when students engage in exploratory talk they are able to draw on their out-of-school Discourse to make meaning and interact within the classroom community (Gee, 2002; Vygotsky, 1978). For example, in this analysis turns 52 to 58 exhibited a communicative struggle and co-construction of ideas when the students were 


\section{Classroom community and discourse: How argumentation emerges during a Socratic circle}

Alexis Carmela Brown

determining whether women are equally respected in lbo culture, the conversation turns to women having to take a man's last name in which one student (S2) claims that his wife will take his last name, while other students groan and disagree.

By making connections between out-of-school Discourse and the formal Discourse of school, such as argumentation structure, students can become members of both in-school and out-of-school Discourses. This analysis starts to address Mercer and Howe's (2012) call for more research that examined the use of exploratory talk for conceptual change. The discourse which students make available to one another can be used to aid in the construction of knowledge and understanding about argumentation discourse, structure and practice. This is demonstrated in the Socratic circle discussion during turn 59 when $\mathrm{S} 1$ references back to textual evidence to support the informal discussion (turns 52 58 ) that previously occurred. The student (S1) recognized that there was a need to bridge the informal talk by bringing the conversation back to formal argumentation through presenting textual evidence.

\section{Educators can mediate formal argumentation practices through dialogic learning such as Socratic circles}

By having students make available to each other elements of argumentation discourse, teachers can use dialogic activities such as Socratic circles to mediate formal argumentation practices. As previous research has identified, teachers' lack of pedagogical skills to foster argumentation, pressure to cover material, and deficient prior knowledge on the part of the learners, are major causes as to why students struggle with understanding formal argumentation (Jonassen \& Kim, 2010). However, some of the above issues can be resolved when teachers allow students to engage in exploratory talk, which uses students' own Discourse. By having the teacher record or film class discussions, teachers are then able to use the recording to mediate student learning about formal argumentation structure. In this discussion students were able to move between informal and formal practices, showing recognition of argumentation structure such as the example in turns 52 to 59 . In other instances students may not have noticed the connections between formal and informal structure, but they have made available the discourse patterns of argumentation, which can be used as a tool to mediate language and understanding (Vygotsky, 1978). Having students listen to, and reflect on, their own discussion will help bring them into formal argumentation discourse.

Fecho et al.(2012) have observed that many students do not see the potential of dialogical educational moments because of the monologic system they are used to. It is through dialogic learning and practices such as Socratic circles that teachers can highlight the value and importance of student Discourse. By mediating formal argumentation practices through dialogic learning, there is an opportunity for students to see the potential of dialogic education. Having students watch their own dialogue on a topic, and linking their own Discourse to formal argumentation structure, will show students what they already know. Thus dialogic learning, and its potential for students will not only be seen by the students, but will create empowering opportunities.

\section{Implications}

I argued that the use of Socratic circles as an appropriate dialogic teaching tool simultaneously increases teachers' repertoires of learning talk and supports critical literacy and argumentation practices. My analysis of the above Socratic circle discussion was aimed at addressing the research gap in dialogic teaching pedagogy at the secondary-level. Through my analysis I sought to demonstrate the importance of exploratory talk as a function of Socratic circles in helping bridge students' Discourse with argumentation discourse practices. Further, my analysis revealed three patterns of discourse that were 


\section{Classroom community and discourse: How argumentation emerges during a Socratic circle}

Alexis Carmela Brown

utilized during exploratory talk - generalizations, communicative struggles, and co-construction of ideas. These patterns of talk functioned to open up dialogue, which led to argumentation practices.

Moreover, I have argued that students' Discourse can be used to demonstrate argumentation structure as students learn that they already have a situated understanding of argumentation practices. Recognizing that students' Discourse is equally valid to academic Discourse is important. Students' Discourse can be used to structure more formal argumentation practices, helping students move more fluidly between the different Discourses. By honoring both students' Discourse and academic Discourse, it will help to close the gap between in-school and out-of-school language, and provide students with opportunities to participate in a democratic society.

Finally, I concluded that educators can mediate formal argumentation practices through dialogic learning such as Socratic circles. Dialogic education, in which students can engage in exploratory talk, makes discourse available to students that can be linked with argumentation practices. By having students participate in dialogic learning, and then using their discussion as a way to mediate understanding, educators could bring students into the discourse of argumentation by making explicit what argumentation looks like. Dunne (2014) argues that schools have been slow to address the explicit teaching of speaking and listening skills, and that even though formative assessment practices are advocated for, many schools still take this practice as a form of tokenism. My analysis shows how educators can take up a dialogic approach to explicit teaching of argumentation skills that go beyond formative assessment in name only.

Socratic circles can help teachers extend learning talk in the classroom while enhancing critical literacy practices. The increase in learning talk will help to create a more dialogic classroom, where power is shared with the students and student Discourse is valued as a tool for learning and understanding. Further research needs to be done on explicit instruction practices for dialogic teaching in secondary-level classrooms, which include using dialogic conversations as a mediation tool to discuss argumentation practices and structure. However, using Socratic circles to mediate student Discourse and formal argumentation is a start to empowering students and enhancing critical literacy skills needed for participation in society.

\section{References}

Abrami, P.C., Bernard, R.M., Borokhovski, E., Waddington, D.I., Wade, C.A., \& Persson, T. (2015). Strategies for teaching students to think critically: A meta-analysis. Review of Educational Research, 85(2), 275 - 314. doi:10.3102/0034654314551063

Alexander, R. (2008). Culture, dialogue and learning: Notes on an emerging pedagogy. In N. Mercer, D.R. Barnes, \& S. Hodgkinson (Eds.) Exploring Talk in school: Inspired by the work of Douglas Barnes (pp.91 - 114). London, UK: Sage Publications.

Aukerman, M., \& Pandya, J. Z. (2013). Rethinking common answers to critical questions about classroom discourse. Language Arts, 91(1), $41-47$.

Bakhtin, M.M. (1984). Problems of Dostoevsky's poetics[electronic resource]. C. Emerson (Ed. \& Trans.). Minneapolis: University of Minnesota Press. Retrieved from http://hdl.handle.net.ezproxy.library.uvic.ca/2027/heb.08865.0001.001

boyd, d.m., \& Ellison, N.B. (2008). Social network sites: Definition, history, and scholarship. Journal of Computer-Mediated Communication, 13, 210 - 230. doi:10.1111/j.1083-6101.2007.00393.x 
Barnes, D. (1976). From communication to curriculum. Harmondsworth, UK: Penguin.

Barnes, D. (2008). Exploratory talk for learning. In N. Mercer, D.R. Barnes, \& S. Hodgkinson (Eds.) Exploring Talk in school: Inspired by the work of Douglas Barnes (pp.1 - 15). London, UK: Sage Publications.

Cazden, C. (2001). Classroom discourse: The language of teaching and learning. Portsmouth, $\mathrm{NH}$ : Heinemann.

Copeland, M. (2005). Socratic Circles: Fostering critical and creative thinking in middle and high school. Portland, Maine: Stenhouse Publishers.

Corbin, J.M., \& Strauss, A. (1990). Grounded theory research: Procedures, canons, and evaluative criteria. Qualitative Sociology, 13(1), 3 - 21. doi:10.1007/BF00988593

Daniel, M.F., \& Gagnon, M. (2011). Developmental process of dialogical critical thinking in groups of pupils aged 4 to 12 years. Creative Education, 2(5), 418 - 428. doi:10.4236/ce.2011.25061

Delpit, L.D. (2006). Other people's children: Cultural conflict in the classroom. New York: New Press.

Dunne, M. (2014). Addressing the Cinderella area: Using masters level study to support secondary English trainee teachers in developing effective teaching and assessment of speaking and listening. English in Education, 48(1), 93 - 107. doi:10.1111/eie.12033

Fecho, B., Coombs, D., \& McAuley, S. (2012). Reclaiming literacy classrooms through critical dialogue. Journal of Adolescent \& Adult Literacy, 55(6), 476 - 482. doi:10.1002/JAAL.00057

Freire, P. (1970). Pedagogy of the oppressed (M. B. Ramos, trans.). New York: Continuum.

Gee, J. P. (1992). Socio-cultural approaches to literacy (literacies). Annual Review of Applied Linguistics, 12, $31-48$.

Gee, J. P. (2002). Discourse and sociocultural studies in reading. In M. L. Kamil, P. B. Mosenthal, P. D. Pearson, \& R. Barr (Eds.), Methods of literacy research: The methodology chapters from the handbook of reading research (Volume III, pp. 118 - 131). Mahwah, NJ: Lawrence Erlbaum Associates.

Gee, J. P. (2003). What video games have to teach us about learning and literacy. New York: Palgrave/Macmillan.

Giglietto, F., Rossi, L., \& Bennato, D. (2012). The open laboratory: Limits and possibilities of using Facebook, Twitter, and Youtube as a research data source. Journal of Technology in Human Services, 30, 145 - 159. doi:10.1080/15228835.2012.743797

Higham, R. J. E., Brindley, S., \& Van de Pol, J. (2014). Shifting the primary focus: Assessing the case for dialogic education in secondary classrooms. Language and Education, 28(1), 86 - 99. doi:10.1080/09500782.2013.771655

Jonassen, D. H., \& Kim, B. (2010). Arguing to learn and learning to argue: Design justifications and guidelines. Educational Technology Research and Development, 58(4), 439 - 457. doi:10.1007/s11423-009-9143-8

Karpf, D. (2012). Social science research methods in internet time. Information, Communication \& Society, 15(5), 639 - 661. doi:10.1080/1369118X.2012.665468

Kuhn, D. (2005). Education for thinking. Cambridge, MA: Harvard University Press. 


\section{Classroom community and discourse: How argumentation emerges during a Socratic circle}

Alexis Carmela Brown

Lange, P.G. (2008). Publicly private and privately public: Social networking on Youtube. Journal of Computer-Mediated Communication, 13, 361 - 380. doi:10.1111/j.1083-6101.2007.00400.x

Luke, A. (2012). Critical literacy: Foundational notes. Theory into Practice, 51(1), 4 - 11. doi:10.1080/00405841.2012.636324

Mercer, N., \& Howe, C. (2012). Explaining the dialogic processes of teaching and learning: The value and potential of sociocultural theory. Learning, Culture and Social Interaction, 1(1), $12-21$. doi:10.1016/j.lcsi.2012.03.001

Msapigo. (2009, November 16). EHS English 2P/1 ${ }^{\text {st }}$ Socratic Seminar Q1 [Video file]. Retrieved from https://www.youtube.com/watch?v=00v5walh_LQ

Murphey, P., Wilkinson, I., Soter, A., Hennessy, M., \& Alexander, J.F., (2009). Examining the effects of classroom discussion on students' comprehension of text: A meta-analysis. Journal of Educational Psychology, 101(3), 740 - 764. doi:10.1037/a0015576

Osborne, J., Simon, S., Christodoulou, A., Howell-Richardson, C., \& Richardson, K. (2013). Learning to argue: A study of four schools and their attempt to develop the use of argumentation as a common instructional practice and its impact on students. Journal of Research in Science Teaching, 50(3), 315 - 347. doi:10.1002/tea.21073

O'Connor, C., \& Michaels, S. (2007). When is dialogue 'dialogic'? Human Development, 50(5), 275 - 285. doi:10.1159/000106415

Reznitskaya, A., Anderson, R.C., Dong, T., Li, Y., Kim, I., \& Kim, S. (2008). Learning to think well: Application of argument schema theory. In C. C. Block \& S. Parris (Eds.), Comprehension instruction: Research-based best practices (pp. 196 - 213). New York, NY: Guilford.

Reznitskaya, A., \& Gregory, M. (2013). Student thought and classroom language: Examining the mechanisms of change in dialogic teaching. Educational Psychologist, 48(2), $114-133$. doi:10.1080/00461520.2013.775898

Sherry, M. B. (2014). Indirect challenges and provocative paraphrases: Using cultural conflict-talk practices to promote students' dialogic participation in whole-class discussions. Research in the Teaching of English, 49(2), 141 - 167.

Styslinger, M. E., \& Overstreet, J. F. (2014). Strengthening argumentative writing with speaking and listening (Socratic) circles. Voices from the Middle, 22(1), 58 - 62.

Vygotsky, L. S. (1978). Mind in society: The development of higher psychological processes. Cambridge, MA: Harvard University Press.

Roth, W.-M., \& Hsu, P. L. (2010). Analyzing communication: Praxis of method. Rotterdam, NL: Sense Publishers.

Zhang, Z., \& Lu, J. (2014). Assessing argumentative representation with bayesian network models in debatable social issues. International Education Studies, 7(11), 120 - 135. doi:10.5539/ies.v7n11p120

\section{(c) EY}

New articles in this journal are licensed under a Creative Commons Attribution 4.0 United States License.

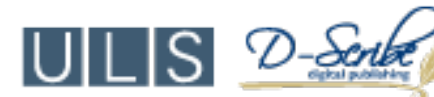

Dialogic Pedagogy: An International Online Journal | http://dpj.pitt.edu DOI: 10.5195/dpj.2016.160 | Vol. 4 (2016) 
This journal is published by the University Library System, University of Pittsburgh as part of its D-Scribe Digital Publishing Program and is cosponsored by the University of Pittsburgh Press. 